\title{
EXPERIENCE WITH AND PERCEPTION OF CLIL BY STUDENT TEACHERS
}

\author{
Zuzana Lukáčová \\ University of Prešov, Slovakia
}

\begin{abstract}
Content and Language Integrated Learning (CLIL) plays a key role in addressing the issue of meaningful and authentic learning. Central to this approach is the concept of a foreign language in a meaningful context while taking into consideration dual aims, i.e. a linguistic and a content aim. The purpose of this paper is to review recent research into the problematics of CLIL and its implementation at primary, lower-secondary and upper-secondary schools as well as to explore the experience with and perception of student teachers towards the CLIL approach. The data were obtained from a semi-structured questionnaire distributed among student teachers of English language and literature (in combination). Based on the data obtained, approximately half of the respondents have had an experience with the CLIL approach in the past. Moreover, the majority of the respondents perceive such an experience as positive. Student teachers' previous experience with CLIL can play an important role in addressing the issue of implementing this approach into teaching by teachers - beginners. Thus, it is believed that the paper will contribute to our understanding of the approach, its implementation at primary, lower-secondary, upper-secondary schools and the perception of the approach by the student teachers of English (in combination) in Slovakia.
\end{abstract}

Keywords: CLIL, content, language, student teacher, teaching.

\section{Introduction}

Approaches and methods represent a major area of interest within the field of (language) methodology. Selection of a proper approach and/or a method can play an important role in addressing the issue of efficient teaching and learning.

Evidence suggests that authenticity and meaningfulness are among the most important factors in the process of learning. CLIL (Content and Language Integrated Learning) has been an object of research since the 1990s. This approach has been instrumental in our understanding of how learning can be pushed forward and become more versatile. Recently, the importance of learning conditions which support authenticity, meaningfulness and discovery processes has been emphasised. According to Coyle, Hood \& Marsh (2010), it is the "authenticity of purpose" (p. 5) which lies at the centre of the CLIL approach. That might be one of the possible reasons why the issue of the CLIL approach has received a considerable critical attention. On the other hand, one must keep in mind that "the curriculum taught in CLIL lessons must comply with the national 
curriculum corresponding to a given content area” (p. 15), as Escobar Urmeneta (2019) points out.

The purpose of this paper is to briefly review recent research into the implementation of the CLIL approach in the classroom. However, the main emphasis is put on the investigation of previous experience of student teachers with the CLIL approach, benefits and possible challenges/obstacles of its implementation, the inclination towards the implementation as well as necessary steps to be taken. The research was conducted at the University of Prešov in Slovakia in 2019. In this article, the abbreviation CLIL will be used to refer to Content and Language Integrated Learning. It is believed the findings will make an important contribution to the field of language learning. The study has been organised in the following way. It has been divided into several parts. Firstly, the study gives a brief overview of the literature around the theme and provides the basic theoretical background to the present approach and its recent history. Then it will go on to the methodology used in the research. The remaining part is concerned with the analysis of data obtained, presentation of the research findings, conclusions drawn alongside with their practical implications.

\section{Literature review}

The history of the CLIL approach traces back to 1994 (Hanesová, 2015). However, it should not be considered as a completely new phenomenon. As the author continues, we can even go back to the ancient history five thousand years ago, when the Akkadians started to use the Sumerian language as a means of instruction after subduing the Sumerians.

A considerable literature has grown up around the theme of the CLIL approach (Mehisto, Marsh, \& Frigols, 2008; Genesee \& Hamayan, 2016; Ball, Clegg, \& Kelly, 2016). Studies such as that conducted by Cenoz, Genesee, \& Gorter (2013) claim that CLIL "has become a well-recognized and useful construct for promoting L2/foreign language teaching” (p. 258). While a variety of definitions of the term CLIL have been suggested, this paper will use the definition by Coyle, Hood and Marsh (2010) who saw it as "a dual-focused educational approach in which an additional language is used for the learning and teaching of both content and language. That is, in the teaching and learning process, there is a focus not only on content, and not only on language. Each is interwoven, even if the emphasis is greater on one or the other at a given time" (p. 1). As Mehisto, Marsh \& Frigols (2008) claim in his work on uncovering CLIL, the purpose of the method is to set the conditions in a way that the following aims can be fulfilled: "Language learning is included in content classes" and "content from subjects is used in language-learning classes" (p. 11). As the author continues, the key element of the entire method of CLIL is integration. According 
to Straková (2013), there are several steps to be taken when a teacher decides to implement CLIL in the classroom, which are: „analysis of the content areas, selection of certain theme, analysis of the content materials, identification of objectives for each unit, identification of key terms and words, selection of appropriate text materials, adaptation or design of new materials“ (pp. 70-71).

When speaking of the essence of CLIL methodology, Mehisto, Marsh \& Frigols (2008) list the following core features: "Multiple focus, safe and enriching learning environment, authenticity, active learning, scaffolding and co-operation" (pp. 29-30). Genesee \& Hayman (2016) put an emphasis on collaboration among teachers as well as their awareness of being both content and language teachers at the same time.

\section{Methodology}

A quantitative research approach was adopted to provide a large-scaled data. To be more specific, a questionnaire was used in order to obtain data to be analysed. The questionnaire was distributed among seventy-six student teachers of bachelor's degree, i.e. teacher training of English language and literature (in combination) at the University of Prešov in Slovakia in 2019. As to the diverse nature of the sample, the following study programmes were involved in the research: teacher training in English language and literature, teacher training in English language and literature in combination with Slovak language, German Language, Russian language, Ukrainian language, Math, Geography, Biology, Civics, Ethics, Aesthetics, History, Physical education.

The nature of the questions asked in the questionnaire was as follows: closeended questions, semi-open questions, open-ended questions. The student teachers were asked eight questions and three sub-questions in total. These questions were predominantly concerned with the student teachers' previous experience with the CLIL approach, possible benefits and drawbacks and obstacles which may occur in its implementation, inclination towards implementing the approach in a future classroom as well as the steps to be taken when introducing the approach.

\section{Data Analysis Research Results}

In this section, the data obtained from the questionnaire will be analysed. Furthermore, the analysis will be accompanied with visual support, i.e. pie/bar graphs and a table. Eight items on the questionnaire were measured, whereas subquestions 2.1, 2.2 and 2.3 were included in order to obtain more detailed data from the respondents. 
The pie chart below shows that the majority of the respondents $(80,26 \%)$ had not come across with the term CLIL before compared to those who either were familiar with the term $(9,21 \%)$ or were not sure $(10,53 \%)$. The reason behind the low number of respondents being familiar with the term might be the fact that the research sample consisted of student teachers of bachelor's degree, i.e. they have not had English language teaching methodology as a proper subject yet. This fact, however, did not prevent from investigating their experience nor the respondents' perceptions since the respondents were explained what CLIL is.

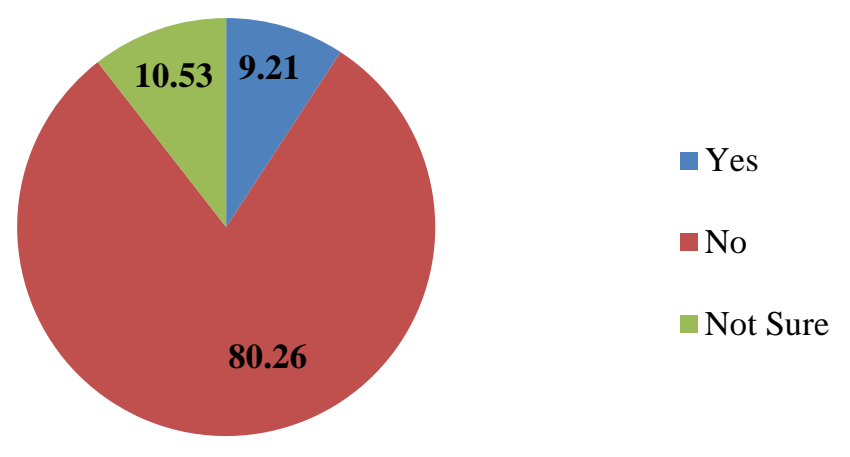

Figure 1 Have you ever heard the term "CLIL" before?

It is apparent from the Figure 2 below that even though the majority of respondents were not familiar with the term per se (as mentioned previously), however, $43,42 \%$ of the respondents had experienced the approach in the past. The remaining part of the respondents either had not experienced the approach or were hesitant about their experience. There is a possibility that some of the undecided respondents had had the experience with the CLIL approach in the past, which could round the "yes percentage" up.

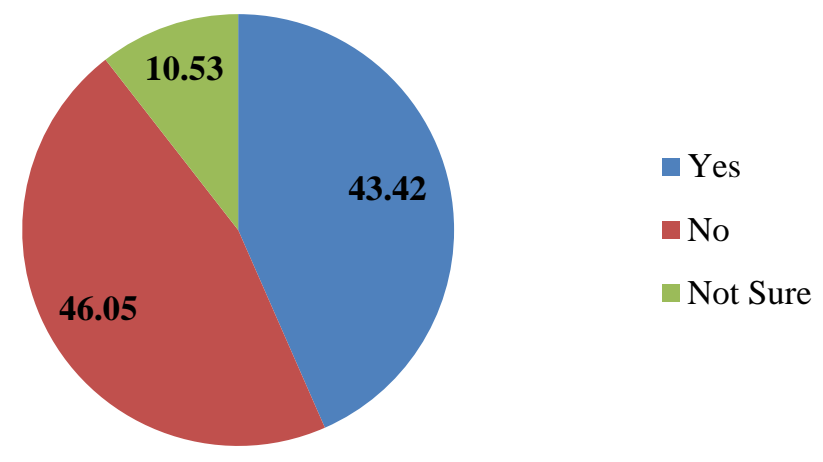

Figure 2 Have you had an experience with the CLIL method in the past?

Those respondents who had experienced the CLIL approach in the past (and some of the undecided respondents) specified the school(s) in which the CLIL approach was used. Based on the data obtained it may be claimed that the majority 
of the respondents $(73,68 \%)$ had experienced the approach at upper-secondary school. The rest of the student teachers involved in the research had had the experience with CLIL at lower-secondary $(31,58 \%)$ or primary school $(7,89 \%)$. The reason why the majority of respondents had experienced CLIL at uppersecondary school might be the fact that the older the students are, the more advanced level of language is, i.e. it may be easier to use a foreign language as a means of instruction. Some of the respondents reported the experience from elsewhere (15,79\%), e.g. teaching practice, language school, Erasmus+, university, grammar school and university and one of the respondents was not sure.

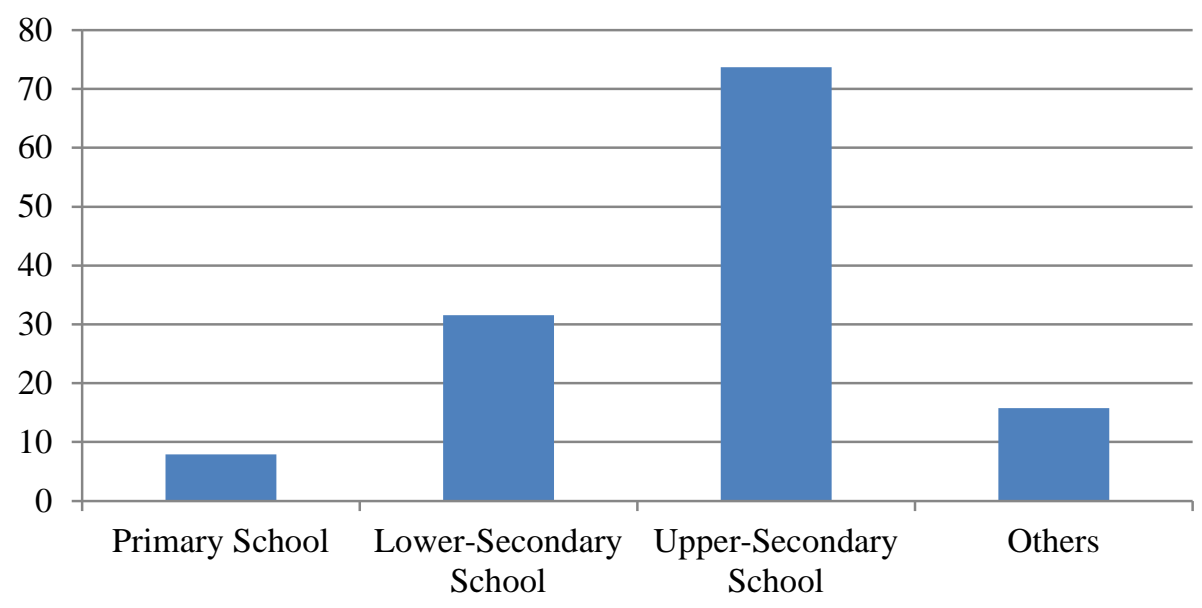

Figure 2.1 Where have you experienced the CLIL method?

When asked about the concrete subjects where the CLIL was implemented, the majority of the student teachers $(84,21 \%)$ chose English language, then German language (15,79\%), French language (7,89\%), Russian language (7,89\%), Spanish language (5,26\%). In other responses (7,89\%) also Italian and Ukrainian languages were mentioned.

Even though a teacher does not necessarily have to integrate language and content only in language classes (see Mehisto, Marsh \& Frigols, 2008, p. 11), it may appear as a more practical option since there is a chance that not all the students share/study the same language. For instance, if a teacher decides to apply CLIL in Math and the language of instruction would be German, there is no guarantee that all students in the classroom actually study German. 


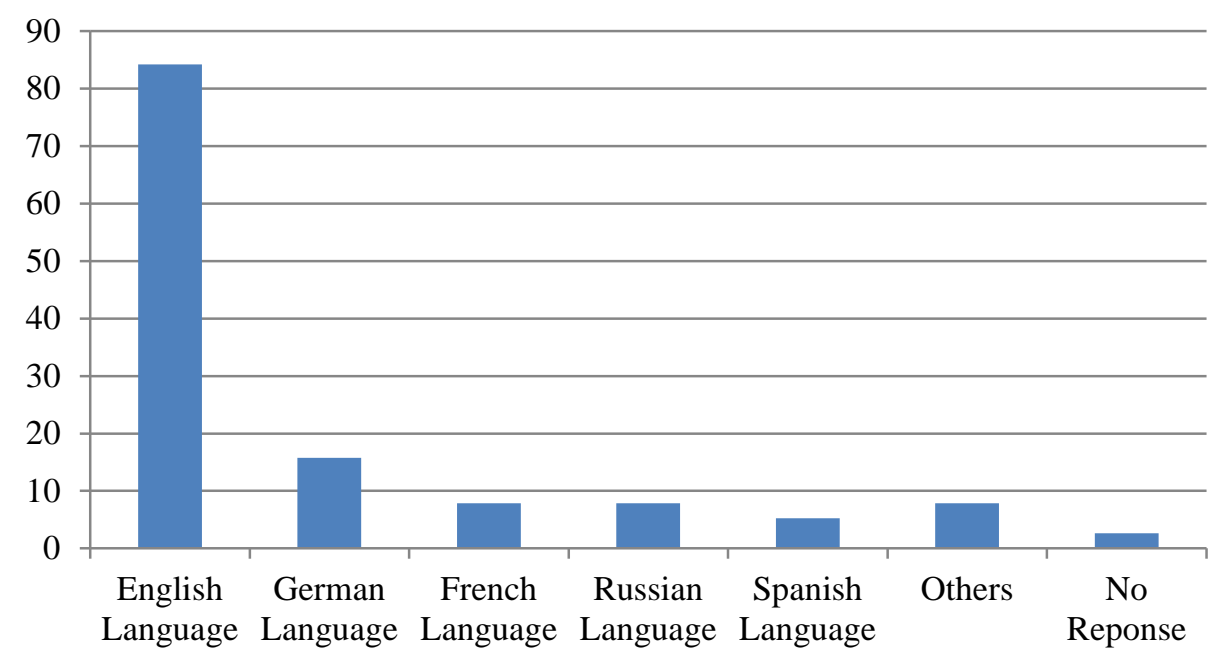

Figure 2.2 Which foreign language was used in the CLIL method?

Interestingly, none of the respondents perceived the experience with the CLIL approach as negative. However, $13,16 \%$ of the respondents remained hesitant. According to Sepešiová (2015), "if learners are expected to succeed they need to be confident in language use as well as in subject knowledge. Confidence is seen possible only in a safe and enriching environment” (p. 131). Thus, it is crucial to create such appropriate conditions in the classroom for proper the implementation of CLIL.

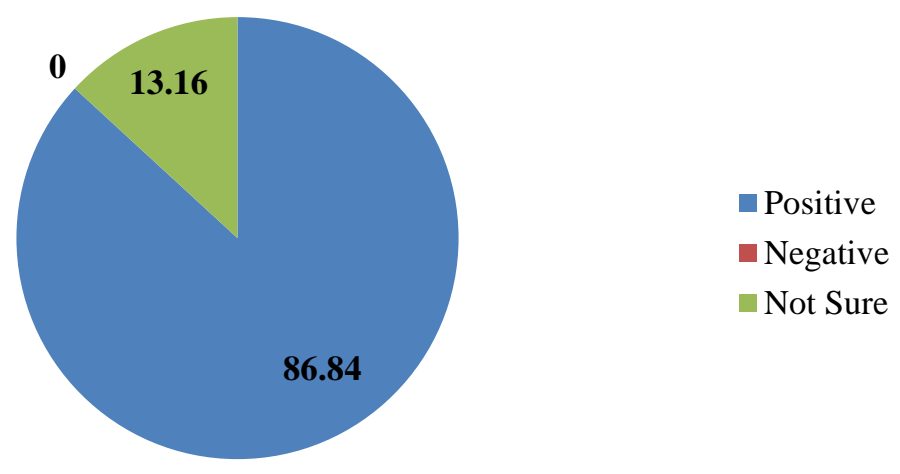

Figure 2.3 How do you perceive the experience with the CLIL method?

When asked about the use of CLIL by nearby schools, half of the respondents were not aware of any school using CLIL in the near area, whereas $18,42 \%$ of the respondents mentioned the following schools: primary school (one respondent), secondary school (seven respondents), grammar school (three respondents), upper-secondary school (two respondents), all of them (one respondent). 31,58\% of the respondents could not agree nor disagree, which points to the possibility of not having enough information about the nearby schooling. Nevertheless, this 
question had rather a limited informative potential. It would be interesting to carry, for example, a discussion or to conduct a focus group on this topic in order to obtain in-depth data.

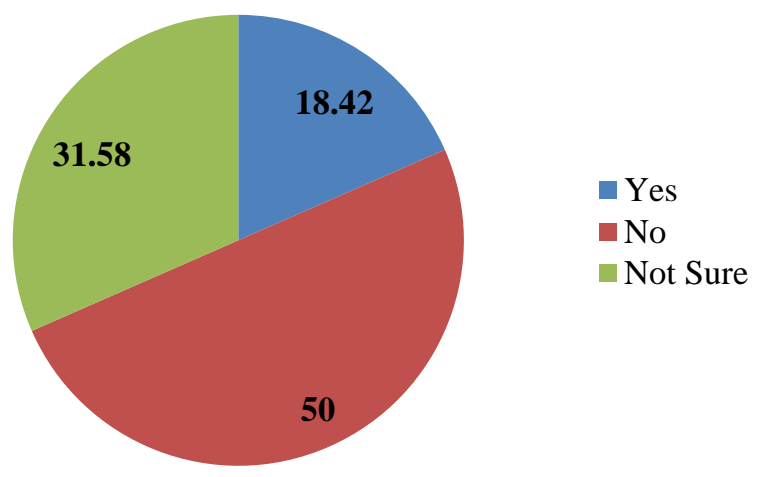

Figure 3 Are you aware of any nearby school(s) that implement(s) the CLIL method into their teaching? If yes, please, indicate whether it is a primary school, lower-secondary, upper-secondary, secondary school or all of them

When speaking of benefits or challenges/obstacles of the CLIL approach, respondents were aware of both. The most valued benefit of the approach was the practical context $(60,53 \%)$ which is applied in the learning process. Another benefit emphasised by the respondents was discovery learning $(47,37 \%)$ which is present in the CLIL lesson as well. The respondents also drew attention to students' motivation being increased $(21,05 \%)$, which plays an important role in every learning process. In addition, authenticity $(7,89 \%)$ was highlighted as the additional value of the CLIL approach.

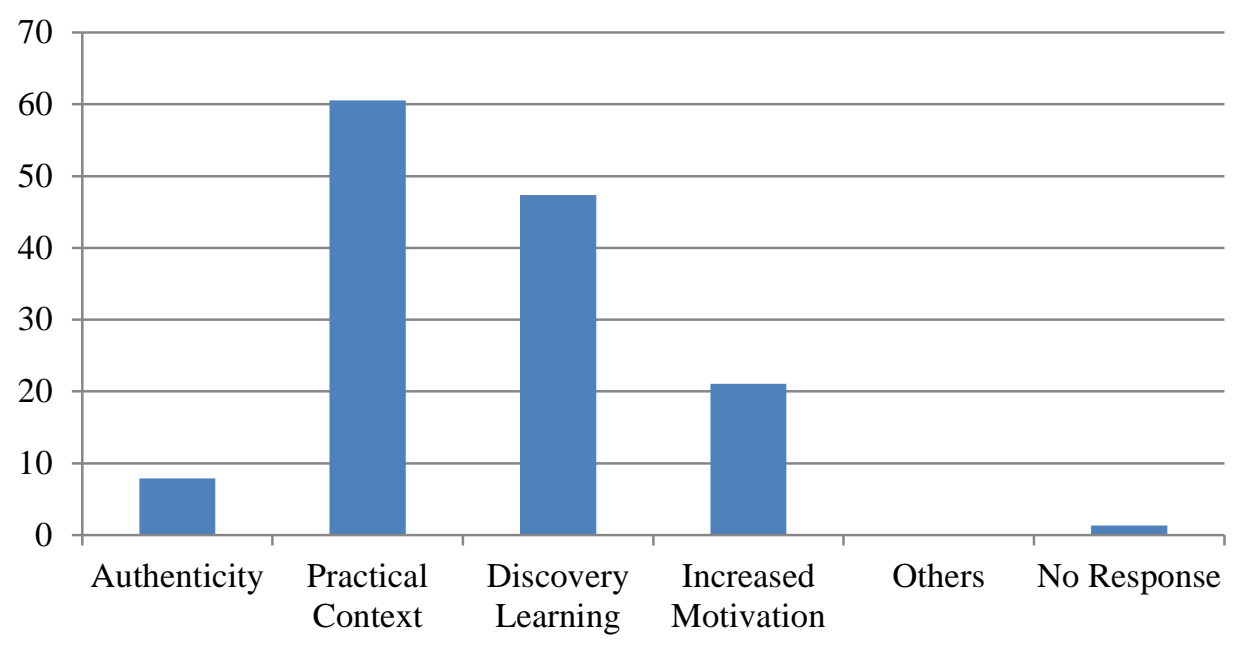

Figure 4 What do you personally consider as the greatest benefit of the CLIL method? 
On the other hand, apart from benefits, challenges and obstacles should be taken into consideration when introducing CLIL to students in the classroom. These challenges include the lack of support from school where teachers teach (51,32\%), extra work for teachers $(35,53 \%)$, fear of failure $(28,95 \%)$, i.e. not fulfilling the stated aims, the lack of support from other teachers $(18,42 \%)$, and others, such as not very positive feedback. Since the research sample consisted of student teachers of English (in combination), it is not probable that a foreign language as such would represent an obstacle. All the challenges and obstacles are part of the implementation process and, thus, are important to be aware of. The fear of not getting enough support from the school indicates that student teachers might not put much belief into surroundings when introducing something new at school. Moreover, the respondents are aware of the responsibility and increased workload which is to be expected when presenting something innovative.

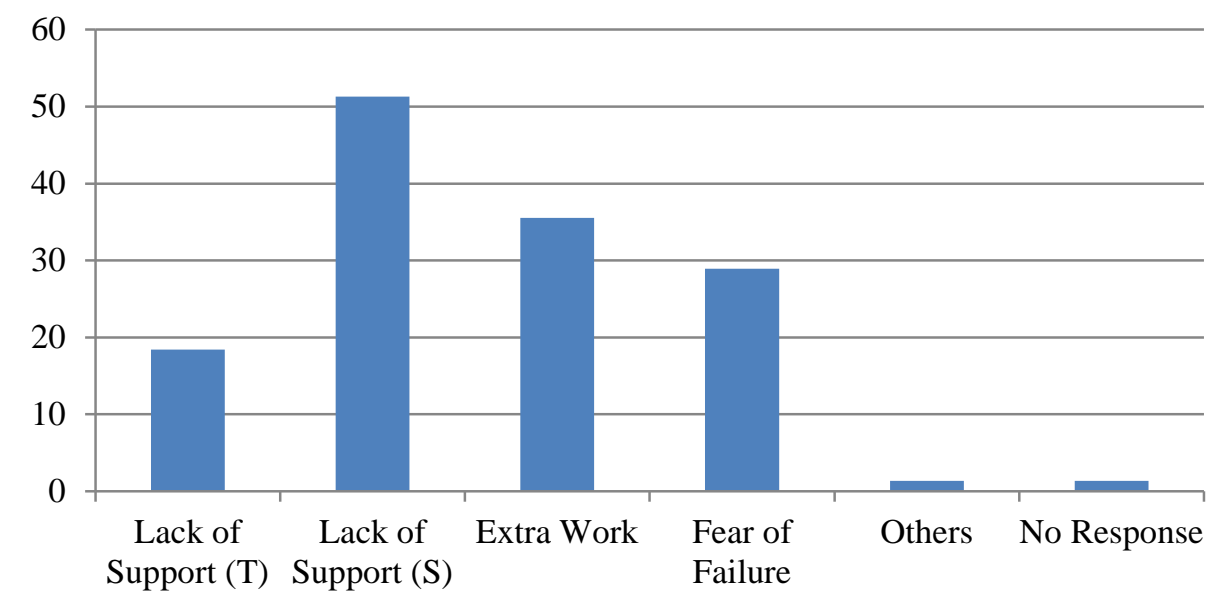

Figure 5 What might be the obstacles for implementing the CLIL method in the classroom?

Surprisingly, more that $65 \%$ of the respondents are either not sure or believe that being a double major graduate is necessary for CLIL. This is a rather interesting outcome pointing out the lack of knowledge about the approach. Even though it may appear less difficult for a double major to work within the CLIL approach, it is not imperative. However, in case of single majors, the need for cooperation and support from other teachers might be, thus, of a greater importance. 


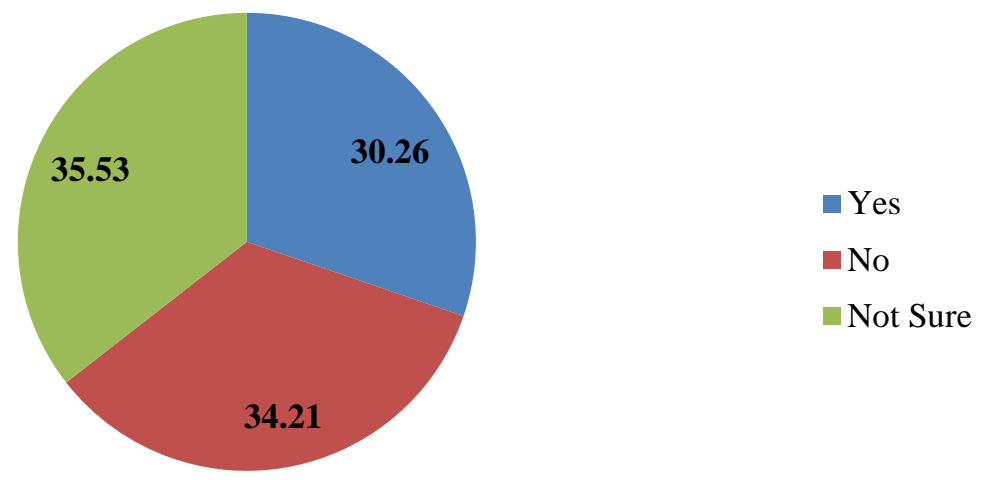

Figure 6 Do you think a teacher has to be a double major graduate in order to teach in the CLIL method effectively?

The following part of the questionnaire required the respondents to give information on whether they could imagine implementing the CLIL approach in their future classroom once they graduate and become teachers. The overall response to this question was very positive. A great number of respondents (80,26\%) answered positively compared to $1,32 \%$ with a negative response. In addition, 18,42\% were still hesitant and, thus, answered "not sure".

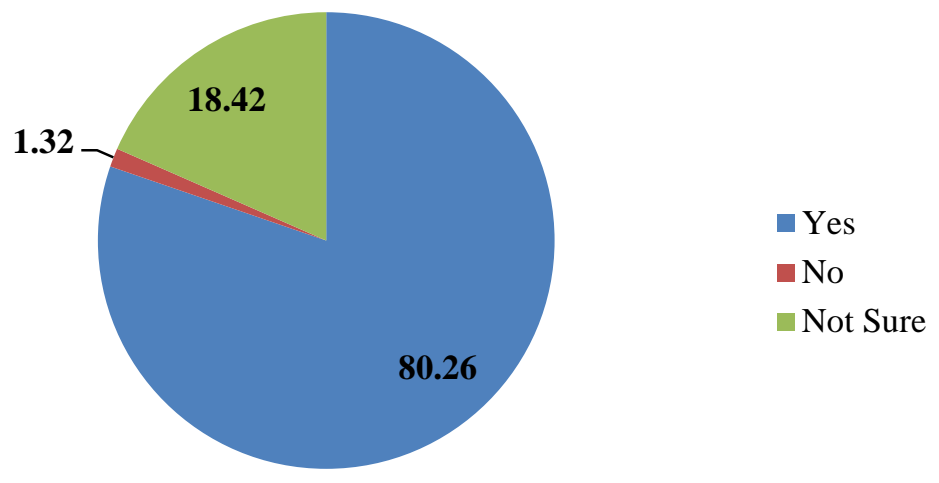

Figure 7 Can you imagine implementing the CLIL method in your own classroom in the future?

The table 1 below provides the overview of various steps that need to be taken when a teacher/lecturer decides to implement CLIL in their classroom. The respondents were asked to put the steps in order according to their preferences starting from the very first step and finishing with the last step. Moreover, the respondents could also include their own step (number 5). The results show that the majority of the respondents consider pre-studying about the approach to be the first step to be taken. As the implementation process would continue, the majority of respondents would try to select proper materials for the CLIL lesson. According to Cimermanová (2017), "the number of ready-made-materials is 
constantly and rapidly growing (especially for soft CLIL; various lesson plans, handouts, but also soft-ware for interactive whiteboards, etc.)” (p. 12). Next step towards introducing CLIL in the classroom would be cooperation with other teachers at school, which should go hand in hand with finding a way how to get support from the school/parents, as the step no. 4 indicates. What is more, a few respondents included other steps that they consider important in the process of CLIL implementation. The steps are as follows: tell students about the method (step 3), get students interested, and others (step 5).

Table 1 Imagine you are about to introduce the CLIL method in your own classroom. Indicate $(1,2,3$... ) which step would be your first, second, third ... to be taken?

\begin{tabular}{|l|c|c|c|c|c|}
\hline & Step 1 & Step 2 & Step 3 & Step 4 & Step 5 \\
\hline Cooperate with other teachers & 0 & 25 & 34 & 16 & 0 \\
\hline Study about the CLIL approach & 65 & 2 & 5 & 3 & 0 \\
\hline Select proper materials & 6 & 29 & 18 & 21 & 1 \\
\hline $\begin{array}{l}\text { Find a way how to get support from the } \\
\text { school/parents }\end{array}$ & 4 & 19 & 17 & 35 & 0 \\
\hline Others & 0 & 0 & 1 & 0 & 2 \\
\hline
\end{tabular}

Taken together, the results suggest that approximately half of the respondents have had an experience with the CLIL approach in the past, especially at upper-secondary during English classes. The majority of the respondents evaluated the experience as positive. Only $18,42 \%$ of the respondents are aware of any schools nearby which use the CLIL approach. Practical context and discovery learning were recognised as the greatest benefits of the approach alongside with the lack of support from school and extra workload for a teacher as possible drawbacks. In the process of CLIL implementation, the majority of the respondents would start with studying about the CLIL approach, then selecting proper materials, cooperating with other teachers, finding a way how to get support from the school/parents.

\section{Conclusion}

The aim of the present research was to investigate whether student teachers of English language and literature (in combination) have had any experience with the CLIL approach in the past and whether the experience itself was more positive or rather negative. Moreover, it was intended to critically explore positive (benefits) and negative (obstacles/challenges) sides of the approach from the point of view of the student teachers as well as steps that need to be taken when implementing CLIL in the classroom. The study set out to gain a better understanding of the approach with the focus on student teachers' perception. This 
study has raised essential questions about the CLIL approach, e.g. the importance of practical context and discovery learning in CLIL as some of the benefits, the student teachers' concerns over the lack of support from the school, implementation of CLIL predominantly at upper-secondary schools, a rather positive experience of student teachers with CLIL as well as their willingness to implement CLIL once they become fully-competent teachers, etc.

The results of this investigation show that the majority of those who have experienced CLIL in the past, perceive it positively. Moreover, the majority of the respondents are inclined to use the approach in future, i.e. once they become teachers. In general, it seems that the respondents are aware of both positives and negatives, i.e. obstacles/challenges with regard to the approach. The current data highlight the importance of teachers' collaboration and school support in promoting the approach. The findings from this study make several contributions to the current literature and have significant implications for understanding what needs to be taken into consideration when introducing the approach to students, such as background research on the CLIL approach, selection of proper materials, cooperation with other teachers - colleagues, getting support from the school and parents, etc. The study provides useful insights into how often CLIL is implemented in different schools as well as its perception by student teachers, i.e. future language teachers. The major limitation of this study is the small research sample. Thus, the generalisability of these results is subject to certain limitations. Further investigation and experimentation into the topic are strongly recommended.

\section{Acknowledgements}

This study derived from a governmentally-funded research project financed by the Slovak Ministry of Education, Science, Research and Sport (research grant number KEGA project No. 032PU-4/2019, project: Vytvorenie učebných materiálov pre učitel'ov základných škôl pre integrovanie jazykového a obsahového vyučovania).

\section{References}

Ball, P., Clegg, J., \& Kelly, K. (2016). Putting CLIL into practice. Oxford: Oxford University Press.

Cenoz, J., Genesee, F., \& Gorter, D. (2013). Critical Analysis of CLIL: Taking Stock and Looking Forward. Applied Linguistics, 35(3), 243-262. DOI: 10.1093/applin/amt011

Cimermanová, I. (2017). CLIL - a Dialogue between the Language and Subject Teachers. Scientia Et Eruditio, 1(1), 1-14. DOI: 10.31262/2585-8556/2017/1/1/1-14

Coyle, D., Hood, P., \& Marsh, D. (2010). CLIL - Content and language integrated learning. Cambridge: Cambridge University Press.

Escobar Urmeneta, C. (2019). An Introduction to Content and Language Integrated Learning (CLIL) for Teachers and Teacher Educators. CLIL Journal of Innovation and Research 
in Plurilingual and Pluricultural Education, 2(1), 7-19. DOI: https://doi.org/10.5565/ rev/clil.21

Genesee, F., \& Hamayan, E.V. (2016). CLIL in context: practical guidance for educators. Cambridge, United Kingdom: Cambridge University Press.

Hanesová D. (2015). History of CLIL. In: Pokrivčáková, S. et al. CLIL in Foreign Language Education: e-textbook for foreign language teachers. Nitra: Constantine the Philosopher University.

Mehisto, P., Marsh, D., \& Frigols María Jesús. (2008). Uncovering CLIL: Content and Language Integrated Learning in Bilingual and Multilingual Education. Oxford: Macmillan Education.

Sepešiová, M. (2015). CLIL lesson planning. CLIL in Foreign Language Education: eTextbook for Foreign Language Teachers, 131-152. DOI: 10.17846/clil.2015.131-152

Straková Z., (2013). Introduction to teaching English as a Foreign Language. Prešov: Vydavatel'stvo Prešovskej Univerzity. 